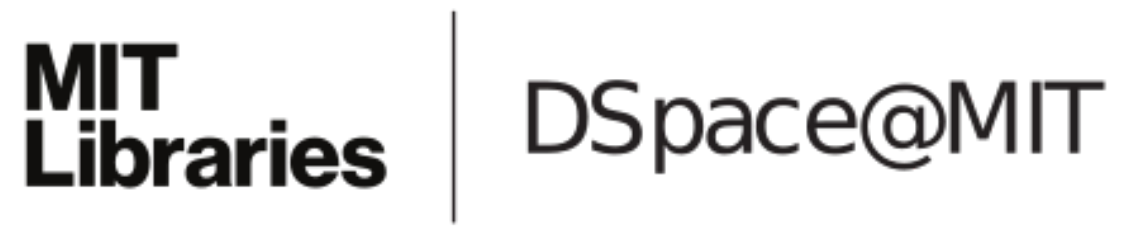

\author{
MIT Open Access Articles
}

The Use of Resources in Resource Acquisition

The MIT Faculty has made this article openly available. Please share how this access benefits you. Your story matters.

Citation: Wernerfelt, B. "Invited Editorial: The Use of Resources in Resource Acquisition." Journal of Management 37.5 (2010): 1369-1373.

As Published: http://dx.doi.org/10.1177/0149206310371693

Publisher: Sage Publications

Persistent URL: http://hdl.handle.net/1721.1/76338

Version: Author's final manuscript: final author's manuscript post peer review, without publisher's formatting or copy editing

Terms of use: Creative Commons Attribution-Noncommercial-Share Alike 3.0 


\title{
The Use of Resources in Resource Acquisition
}

\author{
by
}

\author{
Birger Wernerfelt ${ }^{*}$
}

April 6, 2010

For Journal of Management Special Issue

* MIT Sloan School of Management, Cambridge, MA 02142, bwerner@ mit.edu. I am indebted to the editors for helpful comments. 


\title{
The Use of Resources in Resource Acquisition
}

\author{
Abstract \\ We consider the processes through which a firm can acquire resources and argue that its \\ current stock of resources create asymmetries in competition for new resources. Two \\ simple models illustrate how this can work through linkages on the demand and/or cost \\ side. The normative implication is that firms should expand their resource portfolios by \\ building on their existing resources. Different firms will then acquire different new \\ resources and small initial heterogeneities will amplify over time.
}




\section{INTRODUCTION}

The processes through which firms acquire resources have become a somewhat vexing aspect of the resource based view (RBV). From the very early days of the $\mathrm{RBV}$, scholars have understood that in most reasonable models, if several identical firms compete for a resource, ex ante expected returns will be zero. ${ }^{i}$ Since the idea is that resources support super-normal returns, something has to give. Many scholars have worked on the problem and the debate is still ongoing (Ahuja and Katila, 2004). We here propose a very simple resolution: That a firm's cost of acquiring a new resource and /or the value it can create with this resource, depends on the resources already possessed. This leads to an asymmetry in the "resource market" and allows super-normal profits to be had. ${ }^{\mathrm{ii}}$

We can illustrate both arguments in the context of a winner-take-all patent race. Suppose that the patent goes to the firm expending most "effective effort", which we will think of as a function of a firm's existing resources and the amount of money it invests. A firm which can produce more effective effort per dollar than its competitors should be more likely to win the patent and do so at a price below its value. Similarly, a firm which can extract more value from the patent will be willing to pay more and should be more likely to win and do so at a price below its reservation value.

The formal model can be seen as a very simple an example of chaos and nonlinear dynamics; a case in which small differences in initial conditions cause otherwise identical systems to evolve to very different end states. The closest analog 
is Selove (2009) who looks at a model in which two firms can invest in either of two resources - enabling them to serve either of two market segments. Assuming that the value of resources exhibit increasing returns to scale, he shows that a small initial lag in one segment will cause a firm to focus on the other.

The literature contains many alternative classes of explanations, including appeals to random shocks (Lippman and Rumelt, 1982; Barney, 1986; Ahuja and Katila, 2004), bounded rationality, or claims that some firms simply are better at the acquisition process per se (Teece, Pisano, and Shuen, 1997). We do not address the relative importances of these factors and those introduced here.

We look at cost linkages in Section II, starting with the formal argument and going on to offer several examples. We do the same for value linkages in Section III ${ }^{\mathrm{iii}}$ and conclude with a discussion in Section IV.

\section{CURRENT RESOURCES REDUCING THE COST OF NEW ONES}

\section{$\underline{\text { II.1 Theory }}$}

To isolate the forces driving our argument, we will make several simplifying assumptions. These should not be interpreted as boundaries of the qualitative insights, but as ways to focus on the forces that are first order. We will discuss each assumption in turn.

1. Most pairs of resources are unrelated in the sense that having one will have no effect on the costs of acquiring the other. Furthermore, some resources increase the costs 
of getting specific others. For example, a firm with a large customer base will find it hard to cultivate an exclusive image. These cases are, however, not important. Just as the static version of the RBV tells us not to enter markets in which we "bring nothing to the party", it is clear that the firms should not try to acquire resources for which they have no competitive advantage (or even a competitive disadvantage). So we will concentrate on ordered pairs of resources for which the first (existing) resource reduces the cost of getting the second (target) resource. (We can only talk about ordered pairs because the relation need not be a symmetric: A high end image makes it easier to acquire a large customer base, but not vice versa.)

2. A few resources can reasonably be described by 0/1 variables - you are either endorsed by an independent third party or you are not. However, for most resources it is a question of degree; "how much", "how many", etc. Aiming to keep the argument as simple as possible, we will, nevertheless, look at a target resource that firms either do or do not have. In contrast, the existing resource is one that firms can have more or less of.

3. You do not need a monopoly on a resource to make super-normal profits - small numbers oligopolies will make rents as well. Furthermore, many resources can eventually be imitated such that a monopolist can turn into an oligopolist. A few resources are such that only one firm can have them - patents being the obvious example. We will here focus on the cleaner case of a target resource that can be held by one firm only. In contrast, all firms have some of the existing resource, though generally not equal amounts.

It will be clear to the reader that our qualitative conclusions do not depend on the simplifying assumptions 1, 2, and 3 above (See footnote 4 below). 
Since results are more sensitive to assumptions about the form of competition, we model the resource market in a very general reduced form. We are looking at a game in which two firms compete to acquire a target resource. Competition is symmetric in the sense that all relevant differences between the firms are summarized by their "effective" investments. Specifically, if the firms have $r_{1}$ and $r_{2}$ of the existing resource and make actual investments $a_{1}$ and $a_{2}$, then their effective investments are

$$
e_{i}=a_{i} r_{i}, i=1,2 . .
$$

Given this, if effective investments are $e_{1}$ and $e_{2}$, firm $i$ gets the target resource with probability $p\left(e_{i}, e_{-i}\right)$, where $p()$ is increasing and concave in $e_{i}$ and decreasing and convex in $e_{-i}{ }^{\text {iv }}$ Realizations are dependent such that at most one of the firms wins and $p\left(e_{1}, e_{2}\right)+$ $p\left(e_{2}, e_{1}\right) \leq 1$. To ensure uniqueness, we also make the natural assumption that $\left|\partial^{2} p / \partial e_{i}{ }^{2}\right|>\left|\partial^{2} p / \partial e_{i} \partial e_{j}\right|$, which means that a firm's effective investments have a larger effect on its own marginal returns than those of its opponent. The value of winning is denoted by $v$, which we here assume is the same for both firms.

If both firms understand the situation, their actual investments will be

$$
a_{i} *=\operatorname{Argmax} v p\left(a_{i} r_{i}, a_{-i} * r_{-i}\right)-a_{i}
$$

or

$$
v r_{i} \partial p\left(a_{i} * r_{i}, a_{-i} * r_{-i}\right) / \partial e_{i}=1
$$

Standard tools in economics (the envelope theorem and the implicit function theorem) allow us to conclude that firms with larger $r_{i}$ have larger expected profits, and make larger effective investments ${ }^{v}$, giving them better chances of winning the target resource. 
Since the above argument depends on possibly unfamiliar tools, we now take a brief look at the example in which $p\left(e_{i}, e_{-i}\right)=e_{i} /\left(e_{i},+e_{-i}\right)$. Assuming that $r_{1}$ and $r_{2}$ differ by a factor of less than $3,{ }^{\mathrm{vi}}(2)$ gives $e_{i} * / e_{-i} *=r_{i} / r_{-i}$.

\section{II.2 Examples}

The learning-by-doing examples in Wernerfelt (1984) are of this type. Suppose that it takes two resources, say customer trust and low manufacturing cost, to compete in the market for a new product. If manufacturing cost position is the new resource, more trusted firms can sell more and will thus be able to develop manufacturing skills by moving down the learning curve. If customer trust is the new resource, the idea is that firms with lower cost can develop trust cheaper. In either case, firms can use an existing advantage to earn another.

A big class of examples is that in which the new resource shares some attributes with the existing resource. Consider a fast food chain which has a good reputation as place to have lunch. Such a firm may be able to accelerate the production of a dinner reputation by taking advantage of many of the attributes that built its lunch reputation.

The development of the new resource will often affect the existing resource. The examples described in the above paragraphs suggest that the feedback effect is positive, but this is not always the case. Suppose, for example, that a firm wants to develop a large user-base for a product. This can typically be facilitated by applying a "high end" brand name, although the brand might loose it cache in the process. 


\section{CURRENT RESOURCES ENHANCING THE VALUE OF NEW ONES}

\section{III.1 Theory}

A conceptually different, but formally similar, case is that in which the target resource is worth more to firms with more of the existing resource. So we will concentrate on ordered pairs of resources for which the first (existing) resource increases the value of the second (target) resource. If we describe this relationship by the increasing function $v\left(r_{i}\right)$, the analog of (2) is

$$
a_{i}^{*}=\operatorname{Argmax} v\left(r_{i}\right) p\left(a_{i}, a_{-i}^{*}\right)-a_{i}
$$

Using the same analysis as in Section II, we find that firms with larger $r_{i} \underline{\text { have larger }}$ expected profits, and make larger investments, giving them better chances of winning the target resource. Specifically, if $p\left(a_{i}, a_{-i}\right)=a_{i} /\left(a_{i},+a_{-i}\right)$, we get $a_{i} * / a_{-i} *=v_{i} / v_{-i}$.

\section{III.2 Examples}

This class consists of all cases in which the two resources are complements and thus includes the "manufacturing cost and consumer trust" example mentioned in Section II.2. The lower your cost, the more you gain from trust and vise versa. Another interesting case is that of two-sided networks. For example, a broker with more sellers will put a higher value on more buyers and will thus be willing to invest more in customer acquisition.

Since it takes several resources to make and sell many of the complex products offered in today's markets, complementarity between resources is very widespread. ${ }^{\text {vii }}$ While this tends to favor already resource rich firms, it also exposes them to more risk. 
For example, the value of all complementary resources is reduced if a brand name is destroyed by an unfortunate incident.

\section{DISCUSSION}

We have identified conditions under which firms' existing resources influence their investments in new resources. The analysis contributes to the RBV by proposing an alternative mechanism by which firms add to their stock of resources. The mechanism is close to the spirit of mainstream economics. It does not appeal to luck, bounded rationality, higher order resources, or the like, but simply thinks of the resource acquisition process as an asymmetric investment game.

An important question is whether the forces identified are descriptively important. As a first pass one could look at case histories of individual firms and interpret the development of their resources in light of the argument. To perform a more systematic test, one would have to look at a class of relatively homogeneous situations, such as retailers in different towns or the like. However, given the embryonic state of empirical work on the RBV, this is likely to be very difficult.

We are on firmer ground on the parallel question about normative applicability. The model makes clear and simple suggestions about the direction of investment whenever there are cost- and/or revenue linkages between resources. The advice in the resource market is to build on your strengths - just as the RBV tells you to do in the product market. 


\section{REFERENCES}

Ahuja, G., and Katila, R., "Where do Resources Come From? The Role of Idiosyncratic Situations", Strategic Management Journal, 25, no. 8, pp. 887 - 907, 2004.

Barney, Jay B., "Strategic Factor Markets: Expectations, Luck, and Business Strategy" Management Science, 32, no. 10, pp. 1231 - 41, 1986.

Lippman, Stephen A., and Richard P. Rumelt, "Uncertain Imitability: An Analysis of Interfirm Differences in Efficiency Under Competition”, Bell Journal of Economics, 13, no. 2, pp. 418-38, 1982.

Selove, Matthew, "How do Firms Become Different? A Dynamic Model”, Working Paper, MIT Sloan School of Management, 2009.

Teece, David J., Gary Pisano, and Amy Shuen, "Dynamic Capabilities and Strategic Management”, Strategic Management Journal, 18, no. 7, pp. 509 - 33, 1997.

Wernerfelt, Birger, “A Resource Based View of the Firm”, Strategic Management Journal, 5, no. 2, pp. 171- 80, 1984. 


\section{ENDNOTES}

\footnotetext{
${ }^{\mathrm{i}}$ Barney, 1986
}

ii The idea that resources may create asymmetries in markets for products and resources is not new: Wernerfelt (1984) illustrated this by several examples, but did neither develop, nor stress the point. It has received virtually no attention since then.

${ }^{\text {iii }}$ We consider cost- and value linkages independently for reasons of exposition only. In many cases both forces will be in play and it is even possible that one is negative while the other is positive. The reader will have no problem "netting out" the combined effect. ${ }^{\text {iv }}$ We can drop Assumptions 2 and 3, and assume that several firms can have larger or smaller amounts of the target resource, by reinterpreting $p()$ as the expected amount of the resource going to firm $i$.

${ }^{\mathrm{v}}$ Formally, $d\left(e_{i}-e_{-i}\right) / d r_{i}>0$.

${ }^{v i}$ If the $r$ 's are very different, $\left|\partial^{2} p / \partial e_{i}{ }^{2}\right|<\left|\partial^{2} p / \partial e_{i} \partial e_{j}\right|$.

${ }^{\text {vii }}$ Substitutability is, of course, also very common. However, since firms are at a disadvantage when competing for such resources, they are irrelevant to the resource acquisition process. 